\title{
Toll-like Receptor 2 , Toll-like Receptor 4 Expression and Phagocytic Activity of Neutrophil in Saliva of New Born Babies With Sepsis Risk, An Early Detection Of Neonatal Sepsis
}

\author{
Ari Yunanto ${ }^{1}$, Puji Andayani ${ }^{2}$, Triyawanti ${ }^{3}$, Eko Suhartono ${ }^{4}$, Aris Widodo ${ }^{5}$ \\ ${ }^{1,2}$ Department of Pediatric Ulin Hospital/Faculty of Medicine Lambung Mangkurat University Banjarmasin, \\ ${ }^{3,4}$ Department of Chemistry/Biochemistry Faculty of Medicine Lambung Mangkurat University Banjarmasin \\ ${ }^{5}$ Department of Farmacology Faculty of Medicine Brawijaya University Malang, Indonesia.
}

\begin{abstract}
Neonatal sepsis remains a leading cause of neonatal morbidity and mortality in infant, especially preterm and low birth weight baby. Sepsis is a clinical manifestation of a dysregulated immune response to invasive pathogen.There is increasing evidence that Toll-like receptors (TLRs) play a key role in the mediation of systemic responses to invading pathogens during sepsis. TLRs are essential for triggering the host's immune response, acting as a sensor against invading pathogens. TLR2 was identified as a receptor for gram-positive peptidoglycan and bacterial lipopeptides, whereas TLR4 is part of a receptor complex recognizing gramnegative bacterial.

Saliva is an important body fluid for detecting the physiological and pathological situations of the human body. Neutrophils are considered to participate in the acute response against pathogens in many tissues, and influx into the oral cavity occurs at any time. The expression and function of TLRs greatly influence the quality and control of innate immune response in patients with infectious disease. The high expression of TLRs and phagocytic activity of neutrophil saliva upon presentation of early onset neonatal sepsis patients, suggests this parameter as potential early sepsis biomarker.
\end{abstract}

Key words: early onset neonatal sepsis, TLRs expression, neutrophil saliva phagocytic activity

\section{Introduction}

Since two thousand years ago saliva has been used as a medium to help make the diagnosis of a disease. Even the ancient Chinese traditional medicine, said that the saliva and blood is a "close relative" in the human body, and both come from a single source [1]. Today, a growing appreciation in the use of saliva as a mirror that reflects the characteristics of normal internal and disease status of the individual has progressed. The possibility of the use of saliva as a specimen for diagnosis due to the exchange of compounds that make up the plasma fluid [2]. Several molecular way to get into the saliva from the blood circulation, which passively through diffusion processes, as well as actively through transport intracellular, as well as through the ultrafiltration [3].

Neonatal sepsis is a significant cause of morbidity and mortality, especially in preterm and low birth weight babies. Despite the development of neonatal intensive care units is rapidly increasing, but the case fatality rate (CFR) was ranged from $20 \%$ to $50 \%$ [4]. Neonatal sepsis caused by bacteria in general [5], neutrophils are an important defense mechanism against bacterial infection, will cause the release of neutrophils into the circulation, resulting in an increase in the number of neutrophils in quick time, and will activate TLR2 and TLR4 receptors on neutrophils [6]. Furthermore, after going through the process of phagocytosis, degranulation process will occur, with secretion of several chemical compounds, especially myeloperoxidase (MPO) and lactoferrin (LTF), each of azurophilik granules and specific granules. MPO is expressed in small quantities and is very important to determine the further process of hydrogen peroxide. MPO is usually used as a marker of accumulation of neutrophils in tissue and its a marker of neutrophil activity measured in plasma [7]. LTF is able to inhibit the growth of gram-positive and gram-negative bacteria [8]. Each incident resulted in the formation of phagocytosis phagosome where reactive oxygen species (ROS) and secreted hydrolytic enzymes. ROS can trigger oxidative damage to macromolecules, leading to lipid peroxidation, oxidation of amino acid side chains, formation of protein cross links, produces fragmentation of the polypeptide chain oxidation of proteins, DNA strand breakage [9].

The use of laboratory procedures for diagnostic purposes are most commonly used and involves the analysis of chemical content of the blood cell, but never reported the use of saliva for detection of sepsis in neonates, which can be used as an early marker of neonatal sepsis. Reported the results of studies on the expression of TLR2 and TLR4 and neutrophil phagocytosis activity in saliva of newborns with sepsis risk. 


\section{Material And Methode}

This study is a prospective cross-sectional study, the study has received approval from the Ethics Committee, the saliva and blood samples were taken from 15 newborns with sepsis risk that met the inclusion criteria, saliva and blood samples were taken from 15 newborns with no risk as control, from the parents who have signed informed consent. The study was conducted in July to December 2011, in the Division of Neonatology Section of Child Health Ulin General Hospital / Faculty of Medicine, Lambung Mangkurat University Banjarmasin, All samples was examined in Biomedical Laboratory Faculty of Medicine Brawijaya University Malang. Inclusion criteria: Newborn baby with neonatal sepsis risk is born of mothers who meet the following criteria: 1 major risk or 2 minor risks [10]. Major risks include: rupture of membrane > 24 hours; maternal fever while intrapartum temperature $>38^{\circ} \mathrm{C}$; chorioamnionitis; fetal heart rate settled $>160 \mathrm{x} / \mathrm{min}$; amniotic smell. The minor risks: rupture of membranes> 12 hours; maternal fever when intrapartum temperature $>37.5^{0} \mathrm{C}$; low Apgar score (minute- $1<5$, the $5^{\text {th }}$ minute $<7$ ), very low birth weight infants $(<1,500$ grams) ; gestational age <37 weeks: a multiple pregnancy; vaginal discharge in women who were not treated; women with urinary tract infection (UTI) / suspected UTI untreated. Exclusion criteria: Infants with risk factors for sepsis were born outside of Ulin Hospital; infants with severe congenital abnormalities; infants with severe asphyxia; baby is very very low birth weight.

\section{Isolation of neutrophils: by using the method Gasparoto with modification [11]}

Blood samples: Enter briefly, $6 \mathrm{ml}$ Histopaque 1119 into $15 \mathrm{ml}$ round bottom tube, then $6 \mathrm{ml}$ whole blood werer layered over the gradient, centrifuged $1000 \mathrm{rpm}$ in $30 \mathrm{~min}$. The second band, which contained the neutrophils, was aspirated and washed twice with cold RPMI 1640. Centrifuge $1000 \mathrm{rpm} 10$ minutes and repeat 2-3 times, supernatant removed, the pellet plus $2 \mathrm{cc}$ RPMI medium containing 10\% FBS. The sample was then divided, each $500 \mu \mathrm{L}$ for the test of TLR2, TLR4 expression, number neutrophil and phagocytic activity.

Saliva samples: Saliva plus $3 \mathrm{ml} \mathrm{1:1}$ with $0.9 \% \mathrm{NaCl}$, then vortexed until homogeneous, centrifuge $1400 \mathrm{rpm} 10 \mathrm{~min}$, pellets were washed with PBS pH 7.42 times and then centrifuged, the supernatant was discarded and the pellet taken added 2ml RPMI 10\% FBS, homogenized. The sample was then divided each each $500 \mu \mathrm{L}$ for the test of TLR2, TLR4 expression, number neutrophil and phagocytic activity.

\section{Number of neutrophils, TLR2, TLR4 test}

This test uses flowcitometry. Pellets that are mixed media RPMI centrifuged $1000 \mathrm{rpm}$ for $5 \mathrm{~min}$. Supernatant was discarded, and pellets were given markers (staining) and FITC for CD 64, PE for TLR2 and TLR4 PerCP . 15 min incubation in the dark at room temperature, then add $300 \mu 1$ PBS and 2\% FBS. Read BD Facs Calibur Cell QuestPro modes and data analysis.

\section{Phagocytosis test}

Pellets that are mixed media RPMI put in culture TC 24 well. Incubate $1 \mathrm{hr} 37^{\circ} \mathrm{C} 5 \% \mathrm{CO}_{2}$ incubator. Treatment plus $15 \mathrm{ml}$ bacterial suspension (OD $1=10^{6}$ ), Incubate 30 minutes, and 60 minutes $37^{\circ} \mathrm{C} 5 \% \mathrm{CO} 2$ incubator. Each well pipetted then centrifuged $1000 \mathrm{rpm}$ for $5 \mathrm{~min}$. Supernatant was discarded, pellet was washed PBS pH 7.4 was repeated 2 times. Pellet made smear the glass object, giemsa staining $10 \%$.

\section{Data analysis}

- Comparison of the neutrophils number and the expression of TLR2 and TLR4, respectively blood and saliva samples between case and control groups were tested using independent samples $t$ test

- Comparison of the phagocytosis activity, respectively blood and saliva samples between case and control groups were tested using independent samples t test

\section{Results And Discussion}

Table 1. $t$ test comparison results of saliva in case and control group

\begin{tabular}{lccl}
\hline \multirow{2}{*}{ Variable } & Control group & Case group & \multirow{2}{*}{ p-value } \\
\cline { 2 - 3 } & Mean $\pm \operatorname{SD}(\%)$ & Mean $\pm \operatorname{SD}(\%)$ & \\
\hline $\mathrm{R}$ & $5.63 \pm 6.78$ & $14.43 \pm 12.21$ & 0.021 \\
TLR-2 & $40.06 \pm 23.6$ & $64.97 \pm 26.42$ & 0.011 \\
TLR-4 & $0.57 \pm 0.53$ & $1.5 \pm 1.61$ & 0.044 \\
TLR-2TLR-4 & $8.69 \pm 7.06$ & $23.02 \pm 22.46$ & 0.026 \\
\hline
\end{tabular}

Description : R : Neutrophil count ; TLR : Toll-like Receptor

From Table 1. There is a significant difference / significantly $(\mathrm{p}<\alpha)$ mean $\mathrm{R}$ (neutrophils) in the saliva from the control group $(5.63 \pm 6.78 \%)$ while in the case group $(14.43 \pm 12.21 \%)$. The amount of neutrophils saliva in the case group shows increase if compare to the control group. Similarly, the TLR2 mean in the saliva control group $(40.06 \pm 6.23 \%)$ in the case group $(64.97 \pm 26.42 \%)$, indicating there is a significant differences $(p<\alpha)$. In the case group saliva with neonatal sepsis risk shows increasing TLR2 number than the control group. There's also a significant difference $(\mathrm{p}<\alpha)$ mean TLR4 in saliva 
between the control group $(0.57 \pm 0.53 \%)$ and the case group $(1.5 \pm 1.61 \%)$. The result shows that in the case group saliva with neonatal sepsis risk increase compare to TLR4 control group. While in TLR2-TLR4 between the control group (8.69 \pm $7.06 \%)$ and the case group $(23.02 \pm 22.46 \%)$ shows no significant difference $(\mathrm{p}<\alpha)$. The result of TLR2-TLR4 in the case group saliva with neonatal sepsis risk increase compare to control group.

Table 2. $t$ test comparison results of blood in case and control group

\begin{tabular}{lccl}
\hline \multirow{2}{*}{ Variable } & Control group & Case group & \multirow{2}{*}{ p-value } \\
\cline { 2 - 3 } & Mean $\pm \operatorname{SD}(\%)$ & Mean $\pm \operatorname{SD}(\%)$ & \\
\hline $\mathrm{R}$ & $0.21 \pm 0.09$ & $1.09 \pm 0.61$ & 0.000 \\
TLR2 & $81.74 \pm 11.79$ & $92.51 \pm 5.51$ & 0.003 \\
TLR4 & $0.12 \pm 0.06$ & $1.42 \pm 0.71$ & 0.000 \\
TLR2-TLR4 & $2.85 \pm 2.08$ & $7.17 \pm 5.06$ & 0.005 \\
\hline
\end{tabular}

Description : R : Neutrophil count ; TLR : Toll-like Receptor

From Table 2. indicates that there is a very significant / highly significant $(\mathrm{p}<\alpha)$ mean $\mathrm{R}$ (neutrophils) in the blood between the control group $(0.21 \pm 0.09 \%)$ and the case group $(1.09 \pm 0.61 \%)$. It shows that in blood from case group have increased number of neutrophils compared to the control group. Similarly, the TLR2 mean in the control group (81.74 $\pm 11.79 \%)$ and in the case group $(92.51 \pm 5.51 \%)$ indicates there is a very significant $(\mathrm{p}<\alpha)$. It is clear that in the blood from case group the TLR2 has the high score in control and case group. Also there is a very significant $(p<\alpha)$ between TLR4 in the control group $(0.12 \pm 0.06 \%)$ and the case group $(0.71 \pm 1.42 \%)$. The result shows that in the case group increased if compared to TLR4 control group. While in TLR2-TLR4 mean between the control group $(2.85 \pm 2.08 \%)$ and the case group $(7.17 \pm 5.06 \%)$ indicates there is a very significant $\quad(p<\alpha)$. The result of TLR2-TLR4 in the case group is increase if compare to control group.

Table 3. Comparison of Phagocytosis Index Saliva Neutrophil in Case and Control Group

\begin{tabular}{lccc}
\hline \multirow{2}{*}{ Variable } & Control group & Case group & \multirow{2}{*}{ p-value } \\
\cline { 2 - 3 } & Mean \pm SD & Mean \pm SD & \\
\hline PI (30mnt) & $33.97 \pm 9.34$ & $49.55 \pm 7.69^{\mathrm{a}}$ & 0.000 \\
PI (60mnt) & $65.27 \pm 7.70$ & $75.64 \pm 6.53^{\mathrm{b}}$ & 0.000 \\
\hline
\end{tabular}

Description : PI / Phagocytosis Index=phagocyted neutrophils per total amount neutrophils

In Table 3. show that there is a very significant / significant $(\mathrm{p}<\alpha)$ mean phagocytosis index (30 min observation in saliva between the control group $(33.97 \pm 9: 34)$ and case group $(49.55 \pm 7.69)$ showed there is a very significant / significant $(\mathrm{p}<\alpha)$. It is clear that in the saliva of patients showed increased phagocytosis of neonatal sepsis than in normal patients, seen in the case of the mean value $>$ mean control. Differences were highly significant / significant $(p<\alpha)$ mean phagocytosis (observation 60 minutes) in saliva between the control group $(65.27 \pm 7.70)$ and case group (75.64 $\pm 6: 53)$.

Table 4. Comparison of Phagocytosis Index Blood Neutrophil in Case and Control Group

\begin{tabular}{lccc}
\hline \multirow{2}{*}{ Variable } & Control group & Case group & \multirow{2}{*}{ p-value } \\
\cline { 2 - 3 } & Mean \pm SD & Mean \pm SD & \\
\hline PI (30mnt) & $23.61 \pm 11.24$ & $39.04 \pm 7.49^{\mathrm{a}}$ & 0.000 \\
PI (60mnt) & $46.13 \pm 17.63$ & $72.84 \pm 8.02^{\mathrm{b}}$ & 0.000 \\
\hline
\end{tabular}

Description : PI / Phagocytosis Index=phagocyted neutrophils per total amount neutrophils

In Table 4. there is a very significant / significant $(p<\alpha)$ mean phagocytosis Index (observation 30 minutes) in the blood between the control group (23.61 $\pm 11: 24)$ and case group (39.04 $\pm 7: 49)$ shows there is a very significant / significant $(\mathrm{p}<\alpha)$. It is clear that the patient's blood showed increased phagocytosis of neonatal sepsis than in normal patients, seen in the case of the mean value > mean control. There is a very significant / significant $\quad(\mathrm{p}<\alpha)$ mean phagocytic index (observation 60 minutes) in the blood between the control group $(46.13 \pm 17.63)$ and case group $(72.84 \pm 8: 02)$.

Neutrophils is the first line of phagocytic cells in the natural immune system, and neutrophil amount in a normal newborn higher than in child and adult [12]. In this study, TLR2, TLR4 number and phagocytic activity neutrophils in saliva and blood case groups are significantly higher than control group. According to other neonatal sepsis studies $[13,14]$, our research showed that neutrophils amount is significantly increased as evidenced by the elevation of neutrophil CD64 which is a very sensitive marker. Bhandari et al. (2008) reported that the combination of CD64 with an absolute neutrophil amount had a highly negative predictive value (93\%) and sensitivity test (95\%), for sepsis markers [14]. Vieman et al. (2005) who conducted the TLR2 and TLR4 expression study on granulocytes and monocytes from peripheral veins of 20 healthy adults and from umbilical cord veins of 85 newborn babies (32 sepsis babies and 53 healthy babies), resulted that TLR2 expression in healthy babies slightly lower than healthy adults, while the TLR4 expression in both groups resulted no significant difference. But there was a TLR2 significant up-regulation in the group of sepsis babies compared to healthy babies, based on CRP, IL-6 and IL-8 results. While TLR4 expression in sepsis babies compared to healthy babies, there was no significant difference [15]. It is consistent with this study, which shows the TLR2 
expression was significantly higher in the case compared to control group babies. But in this study the TLR4 expression also shows a significant elevation. In contrast to other studies, babies with respiratory syncytial virus/RSV bronchiolitis had a significant decrease in neutrophil TLR4 expression [16].

It is been proved that saliva has many benefits $[17,18]$, which are contain antimicrobial compounds, and it's use as biomarkers of infectious diseases [19,20], malignancy [21,22], and neutrophil levels in saliva may also indicate successful bone marrow transplant [23]. In this study, saliva case group has increase the mean amount of neutrophils significantly compared to control group. Although neutrophils participate in the acute response against microbial pathogens in various tissues, influx into the oral cavity occur at any time. Neutrophil influx occurred as a result of chemo-attractant factors that found in an oral environment includes microorganisms, toxins, chemokines, and cellular degradation products [11]. Similar results in blood case group has increase the mean number of neutrophils significantly compared to control group. Futhermore, if comparing saliva and blood case group, the neutrophils amount was increased significantly in saliva compared to blood, it proved that the neutrophils activation has been started early in saliva. This study also found the increasing of TLR2 expression significantly in saliva and blood case group compared to control. The increasing of TLR2 expression in this study are consistent with Williams et al. (2003) on animal study, and Vieman et al. (2005) in neonatal sepsis [14,24], the increased of TLR2 expression may be used as an early marker of sepsis [25].

\section{Conclusion}

To some of there is a correlation between saliva and blood variables. The increasing of TLRs expression, amount and phagocytic activity of neutrophils may be use as an early marker of neonatal sepsis. Further research is needed to expand the saliva usage as an early-onset neonatal sepsis biomarker. A better understanding of TLR biology may unveil novel therapeutic approaches for sepsis, for decreasing morbidity and mortality caused by neonatal sepsis.

\section{Acknowledgement}

Thanks are due to Wahyuda Ngatiri Lady, S.Si and all staff members of Biomedic Laboratory Department Faculty of Medicine Brawijaya University, for their kind help and attention.

\section{References}

[1]. Hu Z. The history of saliva. In : Saliva Based Translational Research \& Clinical Application (StarCA). UCLA School of Dentistry, 2008.

[2]. Lima DP, Diniz DG, Sumida DH, Moimaz SAS. Okamoto AC. Saliva: reflection of the body 2009

[3]. Kaufman E, Lamster IB. The diagnostic applications of saliva: a review. Critical Review Oral Biology Medicine 13(2), 2002, 197212.

[4]. Bizzaro JM, Raskind C, Baltimore RS, Gallagher PG. Seventy-five years of neonatal sepsis at Yale : 1928-2003. Pediatric 116(3), 2005, 595-602

[5]. Vergnano S, Sharland M, Kazembe P. et al. Sepsis: an international perspective. Arch Dis Child Fetal 90, 2005, 220-224

[6]. Quinn MT, Gauss KA. Structure and regulation of the neutrophil respiratory burst oxidase:comparison with nonphagocyte oxidases. Journal Leukocyte Biology 76, 2004, 760-781.

[7]. Vrba J, Modriansky M. Respiratory burst of Kupffer cells: target for liver injury treatment. Biomedical Papers 146(2), 2002, 15-20.

[8]. Majerle A, Kidri Q. Jerala Reenhancement of antibacterial and lipopolysaccharide binding activities of a human lactoferrin peptide fragment by the addition of acyl chain. Journal of Antimicrobial Chemotherapy 51, 2003, 1159-1165.

[9]. Segal AW. How neutrophils kill microbes. Annu Rev Immunology 9(5), 2005, 197-223.

[10]. Aminullah A. Sepsis pada bayi baru lahir masalah dan penatalaksanaannya, dalam : Yunanto A, Hartoyo E, Andayani P (Penyunting) Proceeding Simposium Nasional I Ikatan Dokter Anak Indonesia Cabang Kalimantan Selatan (Banjarmasin, 2005).

[11]. Gasparoto TH, Vieira NA, Porto VC, Campanelli AP, Lara VS. Ageing exacerbates damage of systemic and salivary neutrophils from patients presenting Candida-related denture stomatitis. Immunity and Ageing 6(3), 2009, 1-12.

[12]. Urlichs R, Speer CP. Neutrophil function in preterm and term infant. Neorev 5, 2004, e417-e429.

[13]. Anwer SK, Mustafa S. Rapid identification of neonatal sepsis. JPMA 50, 2000, 94-102.

[14]. Bhandari V, Wang C, Rinder C, Rinder H. Hematologic profile of sepsis in neonates: neutrophil CD64 as a diagnostic marker. Pediatrics 121(1), 2008, 129-134.

[15]. Viemann D, Dubbel G, Schleifenbaum S. et al. Expression of Toll-like receptor in neonatal sepsis. Pediatr Res 58(4), 2005, 654-659.

[16]. Halfhide CP, Brearey SP, Flanagan BF. et al. Neutrophil TLR4 expression is reduced in the airways of infants with severe bronchiolitis. Thorax 64, 2009, 798-805

[17]. Samaranayake N. Is saliva the magic diagnostic fluid we were waiting for ?. The Saudi Dent J 20, 2008, 3

[18]. Lima DP, Diniz DG, Sumida DH, Moimaz SAS. Okamoto AC. Saliva: reflection of the body. Int J Infect Dis 14(3), 2010, e184-e188.

[19]. Kumar PS, Kumar S, Savadi RC, John J. Nanodentistry: A Paradigm Shift-from Fiction to Reality. J Indian Prosthodont Soc 11(1), 2011, 1-6

[20]. Ogawa K, Furukawa S, Fujita S, et al. Inhibition of Streptococcus mutans biofilm formation by Streptococcus salivarius FruA. Appl Environ Microbiol 77(5), 2011, 157-180.

[21]. Markopoulos AK, Michailidou EZ, Tzimagiorgis G.Salivary markers for oral cancer detection. Open Dent J 4, 2010, 172178.

[22]. Wong DT. Salivary diagnostics powered by nanotechnologies, proteomics and genomics. JADA 137, 2006, 313-21

[23]. Pink R, Simek J, Vondrokova J. et al. Saliva is a diagnostic medium. Biomed Pap Med 152(2), 2009, 103-110.

[24]. William DL, Ha T, Li C. et al. Modulation of tissue Tol-like receptor 2 and 4 during the early phases of polymicrobial sepsis correlates with mortality. Crit Care Med 31(6), 2003, 1808-1818.

[25]. Tsujimoto H, Ono S, Efron PA, et al. Role of Toll-like receptors in the development of sepsis. Shock 29(3), $2008,315-321$. 